\title{
A mathematical model of in vivo bovine blastocyst developmental to gestational Day 15
}

\author{
P. R. Shorten, ${ }^{* 1}$ M. Donnison, ${ }^{*}$ R. M. McDonald, ${ }^{*}$ S. Meier, † A. M. Ledgard, ${ }^{*}$ and D. Berg* \\ ${ }^{*}$ AgResearch Ltd., Ruakura Research Centre, Private Bag 3123, Hamilton 3240, New Zealand \\ †DairyNZ Ltd., Private Bag 3221, Hamilton 3240, New Zealand
}

\begin{abstract}
Bovine embryo growth involves a complex interaction between the developing embryo and the growthpromoting potential of the uterine environment. We have previously established links between embryonic factors (embryo stage, embryo gene expression), maternal factors (progesterone, body condition score), and embryonic growth to $8 \mathrm{~d}$ after bulk transfer of Day 7 in vitro-produced blastocysts. In this study we recovered blastocysts on Days 7 and 15 after artificial insemination to test the hypothesis that in vivo and in vitro embryos follow a similar growth program. We conducted our study using 4 commercial farms and repeated our study over 2 yr $(2014,2015)$, with data available from 2 of the 4 farms in the second year. Morphological and gene expression measurements (196 candidate genes) of the Day 7 embryos were measured and the progesterone concentration of the cows were measured throughout the reproductive cycle as a reflection of the state of the uterine environment. These data were also used to assess the interaction between the uterine environment and the developing embryo and to examine how well Day 7 embryo stage can be predicted from the Day 7 gene expression profile. Progesterone was not a strong predictor of in vivo embryo growth to Day 15. This contrasts with a range of Day 7 embryo transfer studies which demonstrated that progesterone is a very good predictor of embryo growth to Day 15. Our analysis demonstrates that in vivo embryos are 3 times less sensitive to progesterone than in vitro-transferred embryos (up to Day 15). This highlights that caution must be applied when extrapolating the results of in vitro embryo transfer studies to the in vivo situation. The similar variance in measured and predicted (based on Day 15 length) Day 7 embryo stage indicate low stochastic perturbations for in vivo embryo growth (large stochastic growth effects would generate a significantly
\end{abstract}

Received December 17, 2017.

Accepted April 26, 2018.

${ }^{1}$ Corresponding author: paul.shorten@agresearch.co.nz larger standard deviation in measured embryo length on Day 15). We also identified that Day 7 embryo stage could be predicted based on the Day 7 gene expression profile (58\% overall success rate for classification of 5 embryo stages). Our analysis also associated genes with each developmental stage and demonstrates the high level of temporal regulation of genes that occurs during early embryonic development.

Key words: embryo gene expression, embryonic growth model, uterine environment

\section{INTRODUCTION}

The development of the ruminant conceptus is dependent on maternal factors in the uterine luminal fluid for its growth and development. These maternal factors are critical for blastocyst growth, and the importance of uterine gland secretions into the histotroph has been demonstrated by the ablation of uterine gland development in the perinatal ewe resulting in a maternal environment in which embryos fail to successfully elongate (Gray et al., 2002). The endometrium environment of the developing embryo is a key regulator of the timing and rate of production of interferon tau (IFNT), which modulates the luteolytic pathway to permit the establishment and maintenance of pregnancy (Spencer et al., 2007; Shorten et al., 2010). Progesterone is one of the principal regulators of the endometrium during early pregnancy (Bazer et al., 1979; Spencer et al., 2004; Shorten et al., 2010). Elevated progesterone concentrations are associated with an increased conceptus length on Day 15/16 (Garrett et al., 1988; Carter et al., 2008; Shorten et al., 2018) and this is likely due to an indirect effect on the embryo via the uterine environment as opposed to a direct effect of progesterone on the embryo (Clemente et al., 2009; Shorten et al., 2018). Embryonic mortality due to a poor uterine environment is up to 13 to $15 \%$ for cows compared with $3 \%$ in heifers (Berg et al., 2010; Shorten et al., 2018). There is also moderate between-cow variability in embryo survival to Day 15 (at least $\pm 10 \%$ ) in cows with a receptive environment (Shorten et al., 2018), which is consistent with similar 
estimates from sheep (Shorten et al., 2013). Several progesterone-independent and associated factors also influence embryo growth and survival, including nutrition, BCS, and metabolic state of the animal (Roche et al., 2011; Shorten et al., 2018). A combination of factors results in the cow specific modulation of the protein levels present in the uterine luminal fluid (Ledgard et al., 2011). We have demonstrated that lower energy balance over the period from transfer (Day 7) to recovery (Day 15) was associated with reduced embryo growth to Day 15 and this effect was independent of energy balance effects on progesterone (Shorten et al., 2018). We have also found that that energy balance likely has direct, immediate effects on the embryo and maternal environment during the period from embryo transfer (ET; Day 7) to recovery (Day 15; Shorten et al., 2018). Furthermore, energy balance effects on embryo survival in cows with partial embryo losses (not all of 5 ET embryos were lost by Day 15) were largely mediated by TKDP1, PAG11, and PDPN expression in the embryo (Shorten et al., 2018).

However, the embryo also contributes to its growth trajectory during the preimplantation stage and influences the pregnancy outcome (Ulbrich et al., 2012). A small number of embryos $(\sim 5 \%)$ die because of chromosomal abnormalities that halt development (Peters, 1996). Furthermore, the follicular environment plays a role in oocyte developmental competence (Pavlok et al., 1992; Lonergan et al., 1994). We have previously observed a range of conceptus lengths recovered from the same cow on gestational Day 14 or 15 from bulk transfer of in vitro-produced blastocysts (Berg et al., 2010). We have also determined that a larger ET size (cell number) on Day 7 is associated with a longer embryo length on Day 15 and altered embryo INFT and PAG11 on Day 15 (Shorten et al., 2018). Because the rate of IFNT protein secretion by the embryo is also linked to the length of the trophectoderm tissue (Robinson et al., 2006; Shorten et al., 2018), the amount of IFNT in the uterus to signal pregnancy is dependent on the embryo growth rate. This demonstrates the complex interplay between the embryo, maternal uterine environment, and maternal physiological state on embryonic growth.

In this study we recovered blastocysts on Day 7 and 15 after AI to test the hypothesis that in vivo and in vitro embryos follow a similar growth program. The conceptus size, length, stage at Day 7 and 15 and its Day 7 gene expression were compared to determine developmental variability. We used the Day 7 gene expression to test the hypothesis that in vivo bovine embryo stage on Day 7 can be predicted based on the gene expression profile. A mathematical model was also used to assess the role of embryonic (e.g., gene expres- sion) and maternal (e.g., progesterone) factors on the early pre-attachment embryonic growth rate. Unravelling these complex interactions is key to resolving the decline in dairy cow fertility.

\section{MATERIALS AND METHODS}

\section{Progesterone Assay}

Blood from the tail vein was sampled into evacuated heparinized blood tubes (Vacutainer, Becton Dickinson, Auckland, New Zealand) on Days 0, 7, and 15 of the embryo flush cycles for progesterone concentration measurement. Blood samples were immediately placed in ice water, centrifuged at $4^{\circ} \mathrm{C}$ for $15 \mathrm{~min}$ at 1,500 $\times g$, and aspirated plasma was stored at $-20^{\circ} \mathrm{C}$ until assayed.

Progesterone concentrations were measured by New Zealand Veterinary Pathology Ltd. (Hamilton, New Zealand) with an electro chemiluminescence detection system (Elecsys Progesterone II kits, Roche Diagnostics, GmbH, Germany) using an automated clinical immunology analyzer (Roche Modular E170, Hoffmann-La Roche Ltd., Basel, Switzerland). The sensitivity of the progesterone assay was $0.03 \mathrm{ng} \cdot \mathrm{mL}^{-1}$, with a coefficient of variation of less than $5 \%$. Samples measured below the sensitivity of the assay were assigned the value of the sensitivity of the assay ( $2 \%$ of measurements made on Day 0).

\section{Collection of Day 7 Embryo Samples}

Embryo collection occurred on 4 commercial dairy farms situated in the central and upper provinces of the North Island, New Zealand. As part of the farms' standard breeding practice, lactating dairy cattle were artificially inseminated within $12 \mathrm{~h}$ of observed natural estrus. Body condition score at AI (Roche et al., 2004), days postpartum (DPP), and change in BCS from calving to AI (BCS change) were recorded for each cow. Single embryos were subsequently recovered from the uteri $7 \mathrm{~d}$ after AI (Day 0) utilizing standard flushing technique. Embryos were flushed with Compound Sodium Lactate (Baxter Healthcare, Deerfield, IL) supplemented with $0.1 \%$ BSA (ICP Biotechnology, Auckland, New Zealand) and $1 \mathrm{~m} M 3$-[N-morpholino] propanesulfonic acid (MOPS, Sigma Chemical Co., St. Louis, MO). The collected flushing medium (600-800 $\mathrm{mL}$ ) was filtered to consolidate the volume and the embryos were recovered under a Nikon SMZ1500 stereo microscope (Nikon Instruments Inc., Tokyo, Japan). Embryos were evaluated and photographed (Nikon Digital Sight DS-Fi1). All embryos that had developed to at least the morula stage by Day 7 were placed in 
RNAlater (Ambion Inc., Foster City, CA) and stored at $-80^{\circ} \mathrm{C}$ until processing.

\section{Collection of Day 15 Embryo Samples}

Single embryo collection for Day 15 embryos was done using standard embryo flushing technique (Berg et al., 2010) using the same flushing medium and volumes as Day 7 recoveries. The ipsilateral uterine horn was flushed first, and flushing terminated when an intact elongation stage embryo was visually detected during the flushing procedure. The contralateral horn was only flushed if an embryo was not detected or an embryo fragment was recovered. Each uterine flushing was reduced by filtering the contents through a cup filter to approximately $20 \mathrm{~mL}$. This was then transferred to a 90-mm Petri dish and searched as described for Day 7. The embryo was removed and immediately transferred into a $30-\mathrm{mL}$ Petri dish containing EMCARE Holding solution. The length of the embryo was measured and was classified by trophectoderm (TE) length and morphology: spherical, ovoid, elongating $(2-10 \mathrm{~mm})$, tubular $(10-30 \mathrm{~mm})$, or filamentous $(>30 \mathrm{~mm})$. In the case of several TE fragments being found, the length of each fragment was measured and the lengths summed. The embryo was examined for the embryo disc (ED). If the ED was not located, the uterine flushing samples were re-examined for a detached ED. Each ED was photographed after microdissection of the ED from the TE.

\section{Sample Processing, cDNA Production, and Multiplexed Target Enrichment}

Embryos were removed from the RNAlater solution in minimal volume using a finely drawn mouth pipette, washed in PBS $+4 \%$ Tween20 (Sigma Chemical Co.), and placed into $10 \mu \mathrm{L}$ of RNAGEM solution (ZyGEM NZ Ltd., Hamilton, New Zealand) for complete cell lysis, incubated at $75^{\circ} \mathrm{C}$ for $5 \mathrm{~min}$, then immediately placed on ice. The DNA was removed with DNase I treatment at $37^{\circ} \mathrm{C}$ for $5 \mathrm{~min}$, with inactivation of enzyme at $75^{\circ} \mathrm{C}$ for $5 \mathrm{~min}$, followed by placing the sample on ice. Total RNA was then converted to cDNA using $20 \% \mathrm{vol} / \mathrm{vol}$ Superscript VILO MasterMix (Invitrogen, Thermo Fisher Scientific, Waltham, MA) according to the manufacturer's instructions (mix and incubate at $25^{\circ} \mathrm{C}$ for $10 \mathrm{~min}$, incubate at $42^{\circ} \mathrm{C}$ for $120 \mathrm{~min}$ for increased yields of cDNA, and terminate the reaction at $85^{\circ} \mathrm{C}$ for $\left.5 \mathrm{~min}\right)$.

Amplification of 200 specific target genes within the cDNA was performed according to the multiplexed target enrichment (MTE) protocol for single-cell gene expression analysis (Nanostring Technologies, Seattle, WA) using MTE primers designed by Nanostring. The enrichment conditions incorporated $10 \mu \mathrm{L}$ of Taqman PreAmp $2 \times$ master mix (Thermo Fisher Scientific), $2 \mu \mathrm{L}$ of pooled MTE primers, and $10 \mu \mathrm{L}$ of cDNA. Following template denaturation at $94^{\circ} \mathrm{C}$ for $10 \mathrm{~min}$, targeted enrichment was attained through 6 cycles of $94^{\circ} \mathrm{C}$ for $15 \mathrm{~s}$, then $60^{\circ} \mathrm{C}$ for $4 \mathrm{~min}$.

\section{nCounter (Nanostring) Analysis of Gene Transcripts}

Transcript quantification followed a protocol based on the nCounter (Nanostring Technologies) Gene Expression Assay User manual (MAN-C0003-03). Target cDNA species undergo direct molecular barcoding during a $12 \mathrm{~h}, 65^{\circ} \mathrm{C}$ hybridization with excess capture and reporter probe pairs. Using the automated nCounter Prepstation, excess probe is removed, target/probe complexes are eluted and immobilized in a sample cartridge, and the cartridge analyzed on the nCounter Digital Analyzer.

The gene expression of 194 candidate genes was measured on 96 embryos collected in yr 1 using nCounter (Nanostring Technologies). Target genes were selected from a range of literature studies that have examined the role of gene expression on early embryo development (Ghanem et al., 2011; Ozawa et al., 2012; Zhao et al., 2016). The nanostring primer sequences for the 200 genes in this study are listed in Supplemental Table S1 (https://doi.org/10.3168/jds.2017-14306). GAPDH $(H K), H P R T 1, P P I A, S D H A, U B C$, and $Y W H A Z$ were the 6 housekeeping genes. Negative (8) and positive (6) controls were also measured to assess the repeatability of the assay. The mean $\log _{10}$ gene expression in the 8 negative controls ranged from 0.02 to 0.58 (1.05-3.80). Genes with a mean $\log _{10}$ gene expression greater than $0.6(\mathrm{n}=81)$ were assumed to contain information, whereas genes with a mean $\log _{10}$ gene expression less than 0.6 likely contain mostly noise (and were excluded from multivariate linear regression analysis). Based on the 8 negative controls, the measurement error for the nanostring assay is well approximated by a log-normal distribution.

\section{Mathematical Model of Embryo Development}

A mathematical model of the interaction between progesterone (which influences the uterine environment) and blastocyst developmental stage on embryo development was used to analyze the embryo data. The model is described in detail in Shorten et al. (2018), but summarized here for completeness. 
The rate of change in progesterone concentration $(P$; $\left.\mathrm{ng} \cdot \mathrm{mL}^{-1}\right)$ is

$$
\frac{\mathrm{d} P}{\mathrm{~d} t}=k P\left(P_{\max }-P\right), \quad P(0)=P_{0},
$$

where $t$ is time from ovulation (days), $k$ is the rate of progesterone production $\left(\mathrm{ng}^{-1} \cdot \mathrm{mL} \cdot \mathrm{d}^{-1}\right), P_{\max }$ is the maximum progesterone concentration $\left(\mathrm{ng} \cdot \mathrm{mL}^{-1}\right)$, and $P_{0}$ is the Day 0 progesterone concentration $\left(\mathrm{ng} \cdot \mathrm{mL}^{-1}\right.$; Shorten et al., 2010). This model describes the progesterone dynamics during the initial stage of the cycle (Tsai and Wiltbank, 1998).

The IFNT signal around Day 15 is regulated by progesterone (Satterfield et al., 2006) and is due to progesterone-induced changes in the uterine environment and not a direct progesterone effect on the embryo (Clemente et al., 2009). Increased progesterone concentrations during the early luteal phase are also positively associated with embryo survival (Diskin and Morris, 2008; Clemente et al., 2009). To account for these effects the uterine competence $[h(t)$; unitless] is described by

$$
h(t)=a P(t-b),
$$

where $a$ represents the effect of progesterone on the uterine competence $\left(\mathrm{ng}^{-1} \cdot \mathrm{mL}\right), b$ represents the time delay between increasing circulating progesterone and increasing uterine competence (d), $t$ is time from ovulation $(\mathrm{d})$, and $P(t-b)$ is the concentration $\left(\mathrm{ng} \cdot \mathrm{mL}^{-1}\right)$ of progesterone at time $t-b$.

Approximately $5 \mathrm{~d}$ is required for the embryo to travel through the fallopian tube to the uterus whereby embryo growth is determined by the suitability of the uterine environment. Embryo developmental stage is defined by $\log _{10}$ cell number before blastocyst hatching and embryo length ( $\mathrm{mm}$ ) after blastocyst hatching. Embryo size increases exponentially from Day 1 to blastocyst hatching on Day 9 (Ushijima et al., 2009) and the rate of change in embryo developmental stage $\left(A ; \log _{10}\right.$ cell number) before blastocyst hatching is

$$
\frac{\mathrm{d} A}{\mathrm{~d} t}=h_{1}[1-H(t-5)]+h(t)^{n} \times H(t-5), \quad A_{5}=A(5),
$$

where $h_{1}$ is the initial rate of embryo growth $\left(\log _{10}\right.$ cell number $\cdot \mathrm{d}^{-1}$ ), $n$ (unitless) describes the nonlinear relationship between uterine competence and embryo growth, $A_{5}$ is the developmental stage of the embryo on Day 5 ( $\log _{10}$ cell number), and $H(t)$ is the Heaviside switch function:

$$
H(t)=\left\{\begin{array}{ll}
1, & t \geq 0 \\
0, & t<0
\end{array} .\right.
$$

From Day 5 the embryo cell doubling time is inversely proportional to $h(t)^{n}$, and therefore if $n=0.5$ then doubling progesterone decreases the cell doubling time by $30 \%$.

Embryo length increases exponentially from blastocyst hatching on Days 9 to 15 (Morris and Diskin, 2008; Berg et al., 2010). The rate of change in the $\log _{10}$ embryo length $\left(L ; \log _{10} \mathrm{~mm}\right)$ is

$$
\frac{\mathrm{d} L}{\mathrm{~d} t}=g h(t)^{n}, \quad L\left(t_{H}\right)=L_{H}, \quad A\left(t_{H}\right)=A_{H},
$$

where $g$ is a measure of the rate of embryo elongation $\left(\log _{10} \mathrm{~mm} \cdot \mathrm{d}^{-1}\right), n$ describes the nonlinear relationship between uterine competency and embryo elongation, $A_{H}\left(\log _{10}\right.$ cell number) is the embryo stage when elongation is initiated and $t_{H}(\mathrm{~d})$ is the hatching time. The number of cells and length of a hatching blastocyst have been measured (Berg et al., 2010; Spencer, 2013), and we assume that $L_{H}=\log _{10}(0.3) \log _{10} \mathrm{~mm}$ and $A_{H}=$ $\log _{10}(512) \log _{10}$ cells.

The sizes of the embryos on Day 7 were not measured directly, although the embryos measured on Day 7 were classified according to 21 stages $(2,4,6,8,12,16$ cells, M1-4, TM1-3, EB1-3, B1-3, and XB1-2, where $\mathrm{M}=$ morula, $\mathrm{EB}=$ early blastocyst, $\mathrm{B}=$ blastocyst, $\mathrm{XB}$ $=$ expanding blastocyst, and numbers denote embryo grade). Embryo stage was used to determine representative cell sizes from Ushijima et al. (2009), who measured embryo cell number from 122 Day 1 to 9 embryos. The blastocyst stages classified by Ushijima et al. (2009) were early (range 63-101 cells, mean 78.2 cells), normal (range 97-129 cells, mean 117.6 cells), expanding (range 142-193 cells, mean 159.2 cells), and hatching (range 195-235 cells, mean 219.8 cells). Blastocysts in this study were classified based on equidistant points of the $\log _{10}$ cell number range. This classification scheme for embryo size conforms to exponential growth in embryo cell number and the rate of embryo development $\left(h_{1}\right)$ is interpreted on this logarithmic scale.

\section{Model Fitting Procedure}

Nonlinear regression was used to fit the model (Equations [1]-[5]) to the multi-response data (progesterone and $\log _{10}$ embryo length; Bates and Watts, 2007). The variances of the deviations in measurements within response variables were assumed to be constant and possibly dependent, which allowed for the variances in measurement deviations to be different between 
response variables. Embryo length measurements were $\log _{10}$ transformed before model fitting to ensure normally distributed residuals. The model parameter $g$ (Equation [5]) cannot be estimated independently from our data set, and we assumed an equal cell dividing time pre-/post-blastocyst hatching $(g=1)$.

The embryo growth model (Equations [1]-[4]) was fitted to data for each year on the effect of circulating progesterone on embryo stage on Day 7. Day 15 progesterone was not measured in the Day 7 embryo stage study, and Day 15 progesterone was assumed to be 1.98 times the concentration of progesterone on Day 7 for each cow (based on the relationship between Day 7 and Day 15 progesterone in the Day 15 embryo length study). The vector of model fitted parameters was $[a$ $\left.h_{1} k \begin{array}{lll}k & P_{\max } & \\ \end{array}\right]$ (assuming $b=4.75 \mathrm{~d}, n=0.466$, and $A_{0}$ $=1$ ). This analysis provides more accurate estimates of $h_{1}$ than $a$ due to the weak effect of progesterone on embryo growth to Day 7.

The embryo growth model (Equations [1]-[5]) was also fitted to data on the effect of circulating progesterone on embryo length on Day 15 . The vector of model fitted parameters was $\left[a n h_{1} k P_{0} P_{\max }\right]$, assuming $b=$ $4.75 \mathrm{~d}, g=1 \mathrm{~d}, A_{0}=1, h_{1}=0.36 \log _{10}$ cell number $\cdot \mathrm{d}^{-1}$ (yr 1) and $h_{1}=0.40 \log _{10}$ cell number $\cdot \mathrm{d}^{-1}(\mathrm{yr} 2) ; h_{1}$ estimates for each year were based on the nonlinear model-based analysis of the effect of circulating progesterone on embryo stage on Day 7.

Ordinary differential equations (Equation 1-5) were solved using the stiff system solver ode15s in Matlab (MathWorks, Natick, MA). The standard errors in the model parameters were determined using Markov chain Monte Carlo (Gilks et al., 1996). The Markov chain Monte Carlo procedure was also designed to ensure convergence to the global minimum and ensure that the model parameters were optimal.

\section{Statistical Analysis}

The probability of embryo presence on Days 7 and 15 was analyzed using generalized linear models with binomial distribution and logit link (collection error, submission error, short cycling, anestrus, and infected uterus cows were excluded from analysis). Progesterone on Day 7 was the predictor variable (linear and quadratic terms) for each response. Analyses were conducted separately for each year and farm was treated as a fixed effect.

Embryo size on Day 7 was analyzed using a linear regression model with progesterone on Day 7 and Day 0 as the predictor variables (linear and quadratic terms) for each response. Analyses were conducted separately for each year and farm was treated as a fixed effect within year.
Embryo length on Day 15 was analyzed using a linear regression model with progesterone on Day 7 as the predictor variable (linear term) for each response. Analyses were conducted separately for each year and farm was treated as a fixed effect within year. In yr 1, analysis of the Day 15 embryo length data was conducted with farm 4 analyzed separately from farms 1 to 3 . We had 4 farms in yr $1(1,2,3$, and 4$)$ and 2 farms in yr 2 (1 and 4$)$.

The estimated nonlinear model (Equations [1]-[5]) parameters for embryo growth to Day 15 ( $a, n$ in Equations [1]-[5]) were analyzed using a linear regression model with the fixed effect of study (2014 in vivo, 2015 in vivo, and 2012 in vitro studies).

The estimated nonlinear model (Equations [1]-[5]) parameters for embryo growth to Day $7\left(a, h_{1}\right.$ in Equations [1]-[5]) were analyzed using a linear regression model with the fixed effect of study (2014 in vivo, 2015 in vivo, and 2012 in vitro studies).

Sheppard's correction with a mean interval width of 10 cells was used to adjust the estimated variance in the Day 7 embryo cell number (Johnson et al., 2004). Calculations were performed in $\mathrm{R}$ and Matlab (MathWorks).

\section{Partial Least Squares Regression and Linear Discriminant Analysis}

Partial least squares regression (PLSR) was used to develop models to predict Day 7 embryo size, stage, and grade based on gene expression. Partial least squares regression is a widely accepted regression modeling approach that effectively deals with multi-collinear data (Wold et al., 2001). Mean centering was applied as preprocessing for gene expression data (194 genes).

Predictive models were calibrated/validated on the nanostring data. Prior to developing predictive models, each of the samples from the nanostring data set was separated into calibration and validation sets. These sets were generated by sorting each individual attribute and allocating every third sample to the validation set. This ensured that attributes were evenly distributed between calibration/validation sets. The calibration data set was used to calibrate the embryo size models to the nanostring gene expression data.

The number of latent variables (LV) for PLSR models were identified from the calibration data using 10-fold cross-validation with 100 Monte Carlo replicates for cross-validation. Models were constructed using a range of LV from 1 to 50, and to avoid model overfitting, the optimal number of latent variables was determined by selecting the model with the smallest root mean square error (RMSE). The optimal model was then applied to the validation set to generate the coefficient 
of determination $\left(\mathbf{R}^{2}\right)$ and RMSE performance statistics (Cheng and Sun, 2015). The validation slope (b), intercept (a), and bias (expected predicted - observed) were also calculated based on the regression $Y_{\text {measured }}=$ $\mathrm{a}+\mathrm{b} \times \mathrm{Y}_{\text {predicted }}$.

Regularized linear discriminant analysis (LDA) was used to classify Day 7 embryo stage (gamma, delta hyperparameters were estimated to minimize the 5 -fold cross-validation loss). All classes were assumed to have the same pooled variance-covariance matrix, and LDA analysis was restricted to the 54 genes with greatest gene expression (to ensure that the pooled covariance matrix of the training data set was positive definite).

\section{Multivariate Linear Regression}

Multivariate linear regression was used to investigate the effect of Day 0 progesterone, Day 7 progesterone, BCS, grade, and DPP on the Day 7 gene expression and Day 7 embryo size. Relationships were determined on the $\log _{10}$ transformed Day 7 gene expression and embryo size data (a second multivariate linear regression analysis was also conducted to investigate the effect of Day 7 embryo size on the Day 7 gene expression). The analysis was based on the 81 genes with gene expression greater than the limit of detection of the assay (genes with an average $\log _{10}$ gene expression less than 0.6 were deemed to be below the limit of detection of the assay and largely measurement noise). The model characterizes a d-dimensional continuous response vector as a linear combination of predictors $(K-1)$ and an error vector that is multivariate normal distributed. For the ith observation, the multivariate linear regression model for the $\mathrm{d} \times 1$ response vector is

$$
\mathbf{y}_{i}=\mathbf{X}_{i} \beta+\varepsilon_{i}, \quad \varepsilon_{i} \sim M V N_{d}(\mathbf{0}, \mathbf{\Sigma}),
$$

where $\mathbf{X}_{i}$ is the $\mathrm{d} \times \mathrm{K}$ design matrix, $\beta$ is the $\mathrm{K} \times$ 1 vector of regression coefficients, and the errors $(\varepsilon)$ are assumed to be independent between observations and multivariate normal (MVN) distributed with an unstructured (correlated and heteroscedastic) variancecovariance matrix $\boldsymbol{\Sigma}$. Maximum likelihood was used to estimate the regression coefficients and error variance covariance matrix. The inverse of the observed Fisher information matrix was used to determine the standard errors. Because all the independent variables are random variables, a random x's multivariate multiple regression was employed (Rencher, 2002). The F approximation for Wilks' lambda was used to test the overall regression and the role of subsets of the independent variables on the dependent variables (Rencher,
2002). Model residuals were tested for independence with a multivariate normal distribution.

One-way multivariate ANOVA was also used to compare the multivariate means in the gene expression data grouped by embryo stage (M, TM, EB, B, and $\mathrm{XB}$ ). The analysis was based on the 81 genes with gene expression greater than the limit of detection of the assay. Scatter plots were used to visualize the group separation using the first 2 canonical variables. Dendrograms were used to demonstrate the clusters among the group means (based on applying an average distance linkage method to the matrix of Mahalanobis distances between group means).

\section{RESULTS AND DISCUSSION}

Our analysis is split by year $(2014,2015)$, and yr 2 was used to validate the findings from yr 1 . Estimated model parameters are listed in Table 1.

\section{Embryo Growth}

Calibration of the Progesterone Model to Literature Data. The progesterone model (Equation 1) predicts progesterone measured daily on Days 1 to 14 by Tsai and Wiltbank (1998), Mann et al. (2006), Clemente et al. (2009), and Forde et al. (2011) to good accuracy $\left(\mathrm{R}^{2}=0.99\right)$. This indicates that the model provides good predictions of progesterone on days/ times where progesterone was not measured. This is demonstrated in Supplemental Figure S1 (https://doi .org/10.3168/jds.2017-14306) for the Clemente et al. (2009) progesterone dynamics and that 3 measurements of progesterone on Days 1, 7, and 14 can be used by the model (Equation [1]) to provide a good prediction of progesterone. We also found that the estimated model parameters for the Tsai and Wiltbank (1998), Mann et al. (2006), Clemente et al. (2009), and Forde et al. (2011) progesterone dynamics based on a subset of the progesterone data (Days 1, 7, and 14) are not significantly different than those based on the full progesterone data (Days 1-14). Our results with only 3 progesterone measurements on Days 1, 7, and 14 are consistent with our previous results with 4 progesterone measurements on Days 2, 5, 7, and 15 (Shorten et al., 2018).

Embryo Size on Day 7. The distribution in embryo cell number on Day 7 was approximately log normal in each year, consistent with the exponential growth process (Figure 1A). Unfertilized ovulations (UFO) were excluded from analysis $(\mathrm{n}=36$ in yr 1 and $\mathrm{n}=24$ in yr 2). However, in each year there were a significantly greater number of embryos with cell number less than 
32 cells under a log-normal distribution assumption, suggesting that these small embryos form a slow-growing, less viable subpopulation. Second, data from Van Soom et al. (1997) support the 32-cell threshold. Using the in vivo bovine embryo stage, cell numbers, and cell cycle information relative to the LH surge (their Day 0) reported by Van Soom et al. (1997), precompact morula stage (17 to 32 cells) embryos were present on Day 5 after the preovulatory LH surge, which would be our Day 6. If any delay occurred in ovulation/fertilization of the cows that were inseminated at the onset of estrus, it would be possible to have a later stage precompact morula (32 cells) recovered on the morning of our Day 7 . Indeed, very few of the precompact 32-cell embryos were recovered (3\%). Inclusion of these embryos would have little effect on the mean embryo cell numbers. For these reasons embryos with fewer than 32 cells on Day 7 were excluded from further analyses (n
$=34$ embryos out of a total of 196 embryos in yr 1 and $\mathrm{n}=15$ embryos out of a total of 116 embryos in yr 2).

In yr 1 the average cell number was $78 \pm 2.7(\sigma=$ $35 ; \mathrm{n}=162$ ) for embryos with greater than 32 cells and $67 \pm 2.9$ overall $(\sigma=40 ; \mathrm{n}=196)$. In yr 2 the average cell number was $78 \pm 3.2(\sigma=32 ; \mathrm{n}=101)$ for embryos with greater than 32 cells and $69 \pm 3.5(\sigma=$ $38 ; \mathrm{n}=116)$ overall. A significant effect was observed of progesterone on Day 7 on embryo cell number in yr $1\left(\beta_{\mathrm{P}}=0.022 \pm 0.007 ; P=0.003\right)$, although progesterone only explained a small fraction of the variance in embryo cell number on Day $7\left[R^{2}=0.06(0.01,0.14)\right.$, Figure 2A]. However, no significant effect was observed of progesterone on Day 7 on embryo cell number $\left(\beta_{\mathrm{P}}=\right.$ $-0.0036 \pm 0.0075 ; P=0.6)$ in yr 2 , and progesterone on Day 7 does not explain the variance in embryo cell number on Day $7\left(R^{2}=0.01\right.$, Figure $\left.2 A\right)$. No significant relationship was observed between progesterone on Day

Table 1. Table of model parameter descriptions, source, units, and estimates

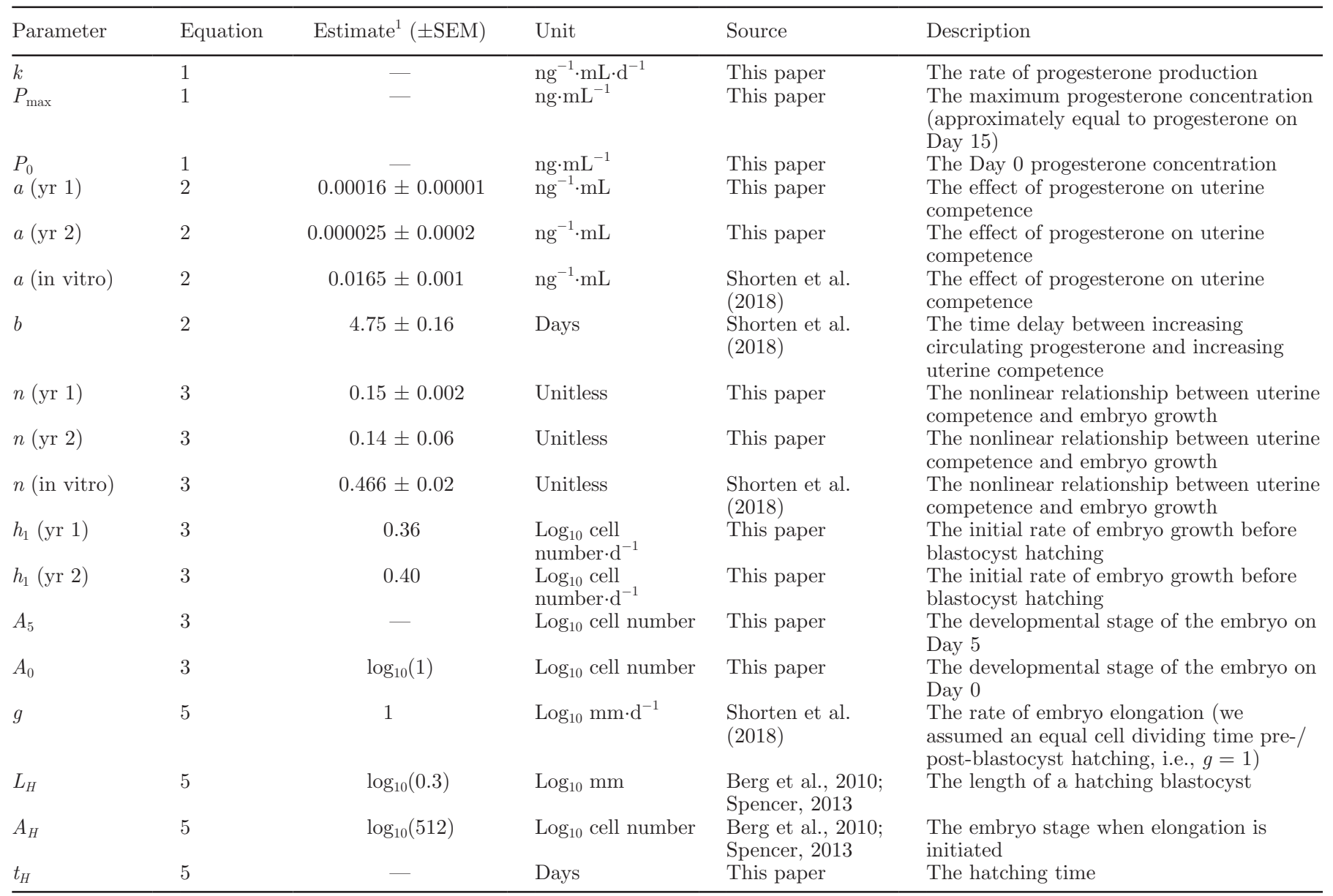

${ }^{1}$ Parameter estimates are reported \pm SEM. Omitted estimates were obtained for each cow but are considered to be input variables that allowed the progesterone dynamics to be accurately interpolated $\left(k, P_{\max }, P_{0}\right.$; Supplemental Figure S1, https://doi.org/10.3168/jds.2017-14306) or intermediate parameters $\left(A_{5}, t_{H}\right)$. 
A)

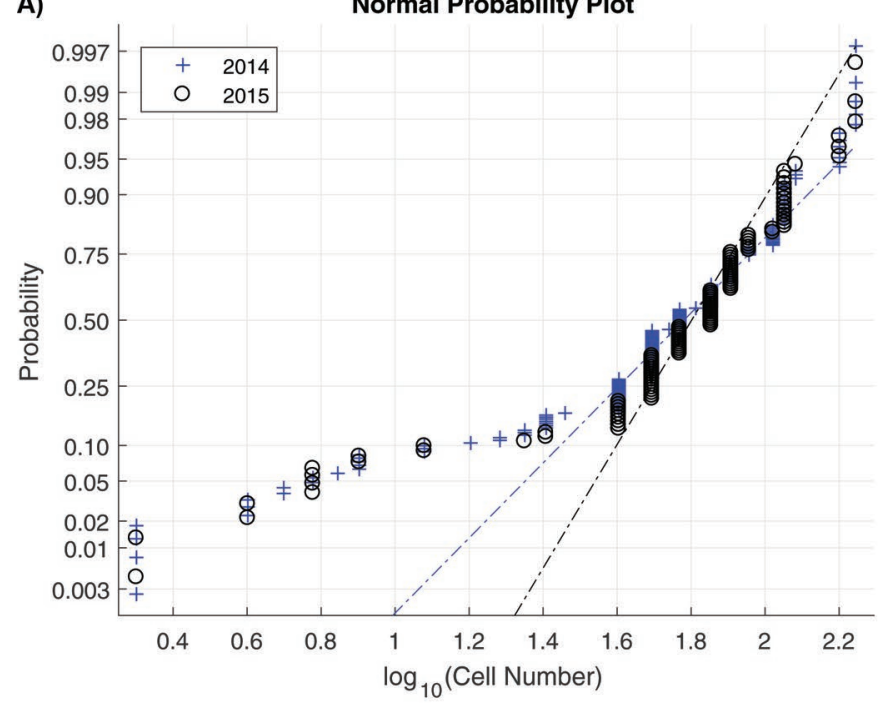

C)

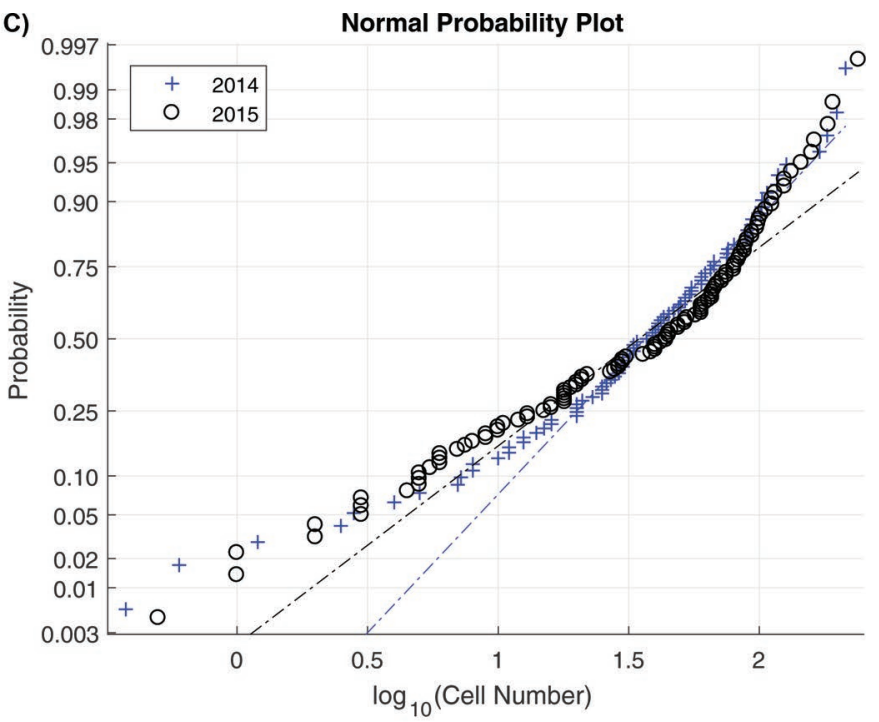

B)

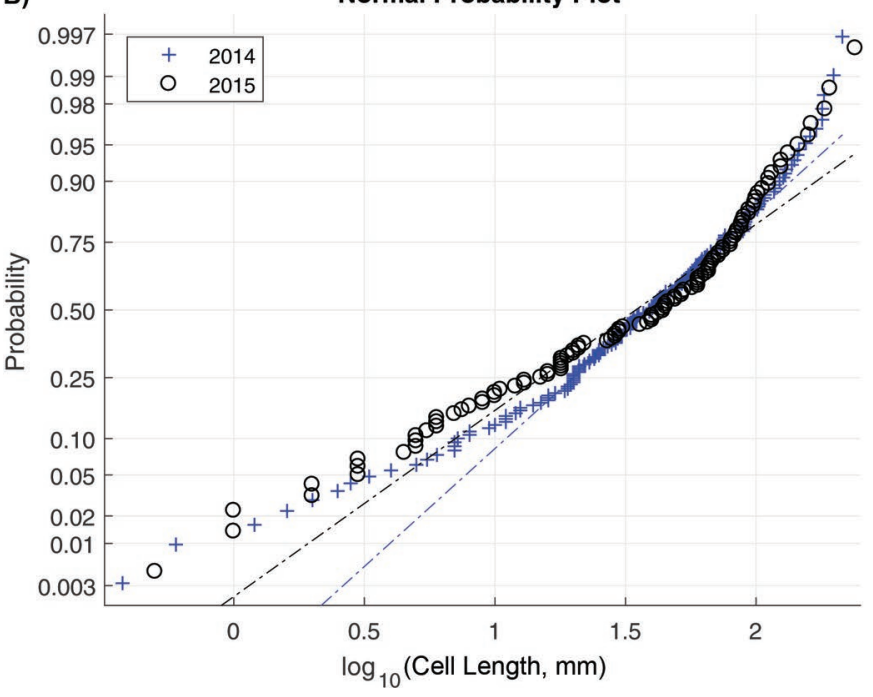

Figure 1. (A) The distribution in embryo cell number on Day 7 is approximately log normal. The dotted lines denote the expected log normal distribution. (B) The distribution in embryo length on Day 15 is approximately log normal. (C) The predicted distribution in embryo size on Day 7 from measured embryo length on Day 15 and progesterone on Days 0, 7, and 15 (2014: farms 1 to 3; 2015: farms 1 and 4). The dotted lines denote the expected log-normal distribution. Color version available online.

0 and embryo cell number in each year, consistent with the low correlation between progesterone on Day 0 and Day 7 in yr $1(\mathrm{R}=0.1 ; P=0.2)$ and $\mathrm{yr} 2(\mathrm{R}=0.35$; $P=0.001$.

Calibration of the Embryo Growth Model with Our Day 7 Data. The embryo growth model (Equations [1]-[4]) was fitted to data for each year on the effect of circulating progesterone on embryo stage on Day 7. The estimated model parameters are $a=0.0011$ $\pm 0.0021 \mathrm{ng}^{-1} \cdot \mathrm{mL}$ and $h_{1}=0.36 \pm 0.008 \log _{10}$ cell number $\cdot \mathrm{d}^{-1}$ in yr 1 and $a=-0.008 \pm 0.009 \mathrm{ng}^{-1} \cdot \mathrm{mL}$ and $h_{1}=0.40 \pm 0.015 \log _{10}$ cell number $\cdot$ day $^{-1}$ in yr 2 (assuming $b=4.75 \mathrm{~d}, n=0.466$, and $A_{0}=1$ ). This very small effect of progesterone on embryo growth up to Day 7 (model parameter $a$ ) is consistent with the 5 d required for the embryo to travel from the fallopian tube to the uterus.

Embryo Length on Day 15. Embryo length on Day 15 was recorded for 155 cows in yr 1, with 26 lengths recorded as a minimum length due to the embryo being observed in pieces (a total of 155 embryos in yr 1). In yr 2 embryo length on Day 15 was recorded for 110 cows, with 10 lengths recorded as a minimum length due to the embryo being observed in pieces (a 
total of 110 embryos in yr 2). Embryo length in cows with lengths recorded as a minimum length due to the embryo being observed in pieces is $50.7 \pm 8.1 \mathrm{~mm}$ in yr 1 and $46.3 \pm 12.7 \mathrm{~mm}$ in yr 2 and are not significantly different than the length of fully intact embryos (54.0 \pm $4.2 \mathrm{~mm}$ in yr 1 and $53.5 \pm 4.8 \mathrm{~mm}$ in yr 2). Therefore, no evidence suggests that our method of summing the lengths of individual fragments to provide an estimate of embryo length in the case of several TE fragments is biased (based on this small sample size).
The overall average embryo length was $53.5 \pm 3.7$ $\mathrm{mm}$ in yr 1 and $52.8 \pm 4.5 \mathrm{~mm}$ in yr 2 when embryos recorded as a minimum length were set to the recorded minimum length (a total of 155 embryos in yr 1 and a total of 110 embryos in yr 2). Embryo length is approximately $\log$ normally distributed in each year (Figure 1B), consistent with the exponential growth process. Log embryo length is not significantly different between farms in yr 1 (Supplemental Figure S2; https://doi .org/10.3168/jds.2017-14306) and yr 2 (Supplemental

\section{$\times 2014$ \\ 2015}

A)

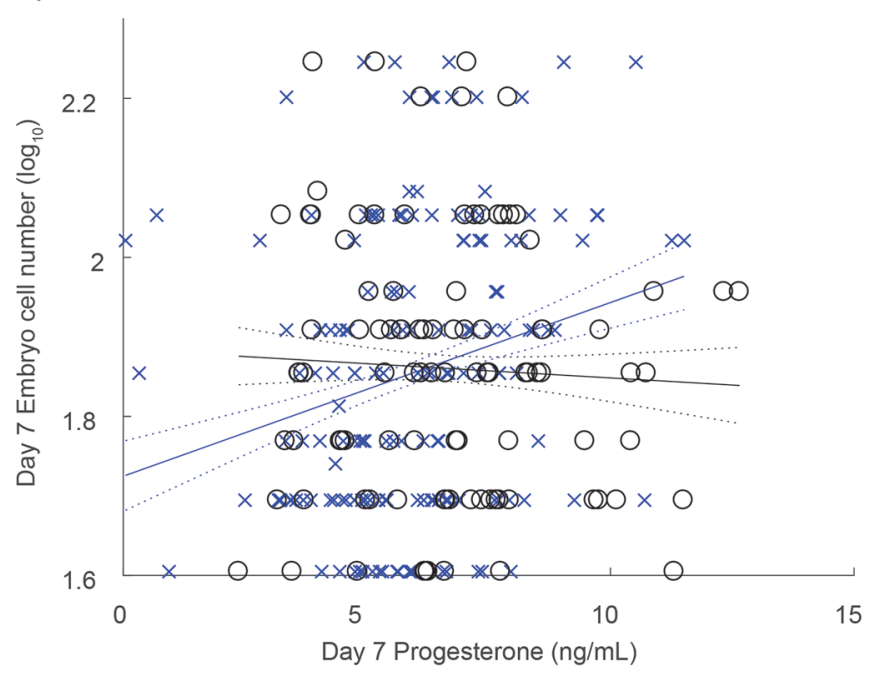

B)

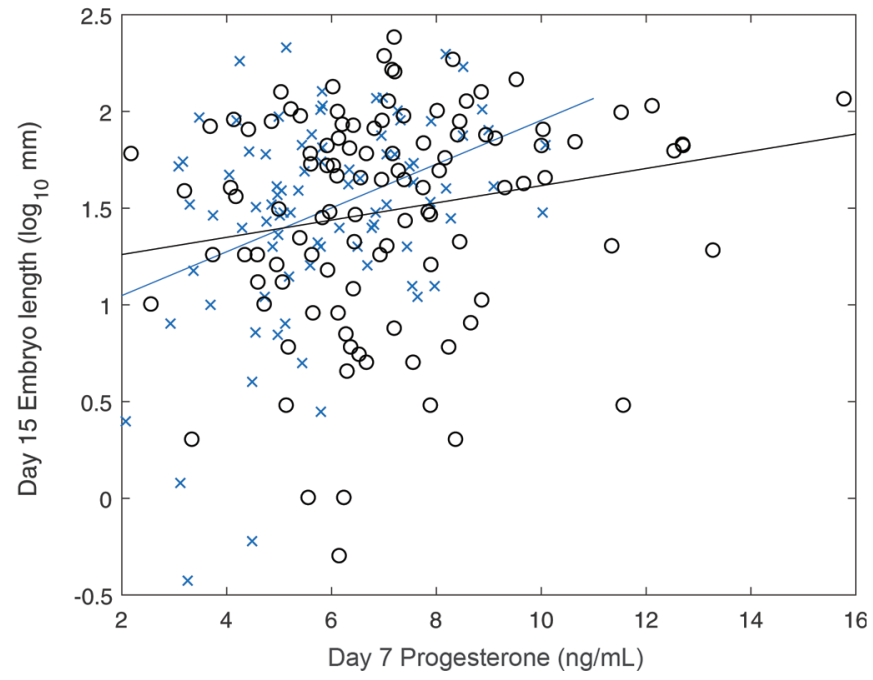

C)

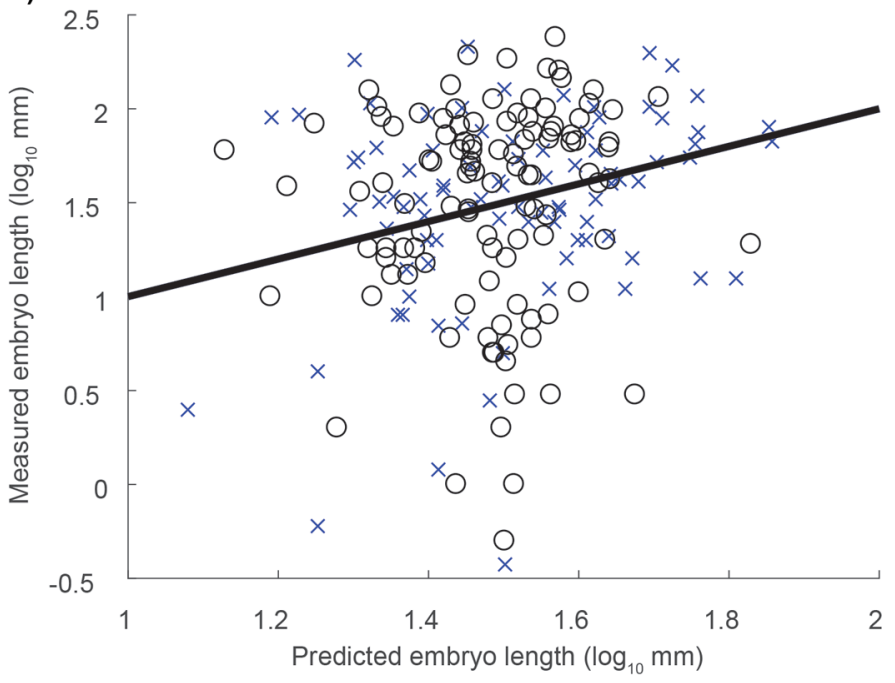

Figure 2. (A) The relationship between Day 7 progesterone and Day 7 embryo cell number $\left(2014: P=0.003, \mathrm{R}^{2}=0.06 ; 2015: P=0.5, \mathrm{R}^{2}\right.$ $=0.01$ ). The solid lines denote the linear regression, and the dotted lines denote SE. (B) The effect of circulating Day 7 progesterone on embryo length on Day 15 (2014: $\mathrm{R}^{2}=0.14, P<0.001$ for farms 1 to $3 ; 2015: \mathrm{R}^{2}=0.04, P=0.04$ for farms 1 and 4 ). (C) The ability of the model to predict embryo length on Day $15\left(2014: \mathrm{R}^{2}=0.08, P=0.01\right.$ for farms 1 to $3 ; 2015: \mathrm{R}^{2}=0.01, P=0.4$ for farms 1 and 4$)$. Color version available online. 
Figure S3; https://doi.org/10.3168/jds.2017-14306). In yr 1 no significant effect was observed of Day 7 progesterone on Day 15 embryo length for farm 4, and the effect of Day 7 progesterone on Day 15 embryo length was significantly different between farm 4 and farms 1 to 3 . The effect of circulating Day 7 progesterone on embryo length on Day 15 (embryos recorded as a minimum length were set to the recorded minimum length) is shown in Figure 2B for yr $1\left(\mathrm{R}^{2}=0.14, P<\right.$ 0.001 for farms 1 to $3 ; \mathrm{n}=87$ embryos $)$ and yr $2\left(\mathrm{R}^{2}\right.$ $=0.04, P=0.04$ for farms 1 and $4 ; \mathrm{n}=109$ embryos). Similar relationships are observed if embryos recorded as a minimum length were excluded from analysis (yr 1: $\mathrm{R}^{2}=0.14, P<0.001$ for farms 1 to 3 ; yr $2: \mathrm{R}^{2}=0.04$, $P=0.05$ for farms 1 and 4 ).

Calibration of the Embryo Growth Model with Our Day 15 Data. The embryo growth model (Equations 1-5) was also fitted to data on the effect of circulating progesterone on embryo length on Day 15 (yr 1: farms 1-3; yr 2: farms 1 and 4). Progesterone on Day 15 is correlated with progesterone on Day 7 in yr 1 $(\mathrm{R}=0.20 ; P=0.02)$ and yr $2(\mathrm{R}=0.47 ; P<0.001)$. The ability of the model to predict embryo length on Day 15 is shown in Figure 2C for yr $1\left(\mathrm{R}^{2}=0.08 ; P\right.$ $=0.01)$ and yr $2\left(\mathrm{R}^{2}=0.01 ; P=0.4\right)$. The estimated model parameters for embryo growth are $a=0.00016$ $\pm 0.00001 \mathrm{ng}^{-1} \cdot \mathrm{mL}, n=0.15 \pm 0.002$ in yr 1 (assuming $g=1, b=4.75 \mathrm{~d}, A_{0}=1$, and $h_{1}=0.36 \log _{10}$ cell number $\cdot \mathrm{d}^{-1}$ ) and $a=0.000025 \pm 0.0002 \mathrm{ng}^{-1} \cdot \mathrm{mL}, n$ $=0.14 \pm 0.06$ in yr 2 (assuming $g=1, b=4.75 \mathrm{~d}, A_{0}$ $=1$, and $h_{1}=0.40 \log _{10}$ cell number $\cdot \mathrm{d}^{-1}$ ), which are significantly different than those estimated from our previous ET study $\left(a=0.0165 \pm 0.001 \mathrm{ng}^{-1} \cdot \mathrm{mL}\right.$ and $\mathrm{n}=0.466 \pm 0.02$, Shorten et al., 2018). If $n=0.15$, then doubling progesterone decreases the doubling time by $10 \pm 0.1 \%$, whereas if $\mathrm{n}=0.466$ then doubling progesterone decreases the doubling time by $28 \pm 1 \%$. The weaker dependence of in vivo embryo growth on progesterone in this trial suggests that either in vitrotransferred embryos are 2 to 3 times more sensitive to progesterone or other factors had a larger effect on embryo growth in the current trial. The estimated effect of progesterone on the cell doubling time $\left[\log _{10}(2)\right.$ $\left.\times(a P)^{-n}\right]$ in the in vitro and in vivo trials is shown in Figure 3. The distribution in embryo cell number on Day 7 and the embryo length on Day 15 from the in vitro ET data (Shorten et al., 2018) are shown in Supplemental Figures S4 and S5 (https://doi.org/10.3168/ jds.2017-14306). Mean Day 7 progesterone in cows with a recovered embryo on Day 15 in the in vitro trial was $5.11 \pm 0.33 \mathrm{ng} \cdot \mathrm{mL}^{-1}$, whereas mean Day 7 progesterone in cows with a recovered embryo on Day 15 in the in vivo trial was $6.08 \pm 0.22 \mathrm{ng} \cdot \mathrm{mL}^{-1}(P=0.02)$ in $\mathrm{yr}$ 1 and $6.99 \pm 0.22 \mathrm{ng} \cdot \mathrm{mL}^{-1}(P<0.01)$ in yr 2 . Day

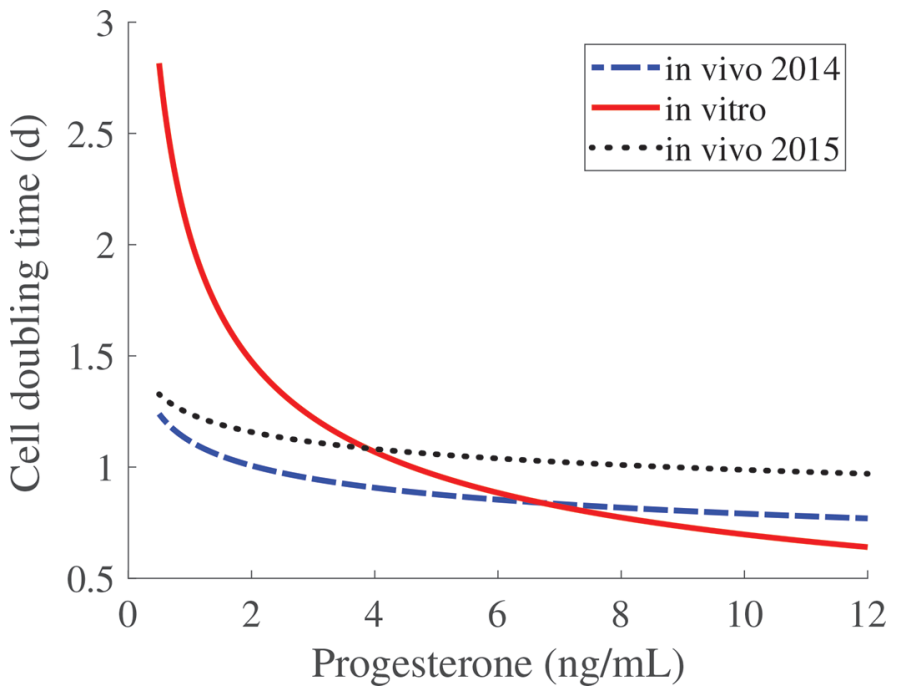

Figure 3. The estimated effects of Day 7 progesterone on cell doubling time in each year of this study (in vivo) and embryo transfer (in vitro; Shorten et al., 2018). The estimated model parameters for embryo growth are $a=0.00016 \pm 0.00001 \mathrm{ng}^{-1} \cdot \mathrm{mL}, n=0.15 \pm 0.002$ in 2014 (assuming $g=1, b=4.75 \mathrm{~d}, A_{0}=1$, and $h_{1}=0.36 \log _{10}$ cell number $\left.\cdot \mathrm{d}^{-1}\right)$ and $a=0.000025 \pm 0.0002 \mathrm{ng}^{-1} \cdot \mathrm{mL}, n=0.14 \pm 0.06$ in 2015 (assuming $g=1, b=4.75 \mathrm{~d}, A_{0}=1$, and $h_{1}=0.40 \log _{10}$ cell number $\left.\cdot \mathrm{d}^{-1}\right)$, which are significantly different than those estimated from our previous embryo transfer study $\left(a=0.0165 \pm 0.001 \mathrm{ng}^{-1} \cdot \mathrm{mL}\right.$ and $n=0.466 \pm 0.02$; Shorten et al., 2018). $a=$ effect of progesterone on uterine competence $\left(\mathrm{ng}^{-1} \cdot \mathrm{mL}\right) ; b=$ time delay between increasing circulating progesterone and increasing uterine competence (d); $g=$ rate of embryo elongation $\left(\log _{10} \mathrm{~mm} \cdot \mathrm{d}^{-1}\right) ; A_{0}=$ developmental stage of the embryo on Day 0 ( $\log _{10}$ cell number $) ; h_{1}=$ initial rate of embryo growth $\left(\log _{10}\right.$ cell number $\left.\cdot \mathrm{d}^{-1}\right) ; n=$ nonlinear relationship between uterine competence and embryo growth. Color version available online.

7 progesterone was also significantly different between yr 1 and $2(P=0.01)$ and demonstrates the level of between trial and between year variability. However, the progesterone dependent doubling time relationship is not significantly different between 2014 and 2015 in vivo trials [the progesterone dependent doubling time is slightly greater in the 2015 trial than the 2014 trial, but this is because the estimate for the initial rate of embryo growth before $\mathrm{d} 5\left(\mathrm{~h}_{1}\right)$ was greater for the 2015 trial than the 2014 trial]. Although the variance in cell number on Day 7 is smaller in the in vitro study, the variance in embryo length on Day 15 in greater in the in vitro study (compare with Supplemental Figures S4 and S5; https://doi.org/10.3168/jds.2017-14306). This suggests that in vitro embryos are more sensitive to progesterone and potentially susceptible to greater stochastic perturbations in embryo growth.

The Distribution in Embryo Size on Days 7 and 15. The embryo growth model (Equations [1]-[5]) was used to predict embryo size on Day 7 from the measurements of progesterone (Days 0, 7, and 15) and embryo length on Day 15 (yr 1: farms 1-3; yr 2: farms 1 and 4). The predicted distributions in embryo size 
on Day 7 is shown in Figure 1C (yr 1: farms $1-3$; yr 2: farms 1 and 4), which have a similar shape to the measured distribution in embryo size on Day 7 in Figure 1A. The similar variance in measured and predicted (based on Day 15 length) Day 7 embryo stage indicate very low stochastic perturbations in embryo growth in vivo. Also, no evidence supports an effect of embryo size on Day 7 on embryo survival to Day 15. This is consistent with our previous ET trial where no effect was observed of transferred embryo size on embryo survival from Day 7 to 15 (Shorten et al., 2018).

\section{Embryo Survival}

Embryo Survival to Day 15. An effect was observed of progesterone on Day 7 on the probability of embryo presence on Day 15 for all farms in yr $1(P=$ $0.03 ; \mathrm{n}=262)$ and farms 1 and 4 in yr $2(\mathrm{n}=165 ; P$ $=0.14$ for linear effects). The expected probability of embryo presence on Day 15 is $0.607 \pm 0.03$ in yr 1 and $0.70 \pm 0.036$ in yr 2 (collection error, submission error, short cycling, anestrus, and infected uterus cows were excluded from analysis). There is no quadratic effect of Day 7 progesterone on the probability of embryo presence on Day 15, although embryo survival tended to be slightly lower for high progesterone on Day 7 in yr $1(P$ $=0.2)$ and yr $2(P=0.14)$. The probability of embryo presence on Day 15 is estimated to increase by $0.032 \pm$ 0.014 per unit increase in progesterone $(\mathrm{ng} / \mathrm{mL})$ in $\mathrm{yr}$ 1 and by $0.09 \pm 0.06$ per unit increase in progesterone $(\mathrm{ng} / \mathrm{mL})$ in yr 2. These estimates are not significantly different and are not significantly different from similar estimates from our previous ET trial $(0.054 \pm 0.017$; $P<0.01)$. No significant between-farm variability was observed in the effect of Day 7 progesterone on the probability of embryo presence on Day 15 in each year $(P=0.4$; Supplemental Figures S6 and S7; https:// doi.org/10.3168/jds.2017-14306). This relationship between progesterone and embryo survival is consistent with the concept that providing progesterone has the maximum benefit when embryo survival is low.

Embryo Survival to Day 7. Progesterone on Day 7 was observed to have an effect on the probability of embryo presence on Day 7 for all farms in yr $1(P$ $=0.03, \mathrm{n}=371)$ and yr $2(P=0.01, \mathrm{n}=203)$. The expected probability of embryo presence on Day 7 is $0.642 \pm 0.025$ in yr 1 and $0.68 \pm 0.033$ in yr 2 (collection error, submission error, short cycling, anestrus, and infected uterus cows were excluded from analysis). The probability of embryo presence on Day 7 is estimated to increase by $0.026 \pm 0.012$ per unit increase in progesterone $(\mathrm{ng} / \mathrm{mL})$ in yr 1 and by $0.17 \pm 0.06$ per unit increase in progesterone $(\mathrm{ng} / \mathrm{mL})$ in yr 2 . These estimates are not significantly different from the re- spective estimated effects of progesterone on Day 7 on the probability of embryo presence on Day 15 in yr 1 $(0.032 \pm 0.014)$ and yr $2(0.09 \pm 0.06)$. No quadratic effect was observed of Day 7 progesterone on the probability of embryo presence on Day 7 in yr $1(P=0.4)$, although Day 7 progesterone had a significant quadratic effect on the probability of embryo presence on Day 7 in yr $2(P=0.02)$. There is no significant between-farm variability in the effect of Day 7 progesterone on the probability of embryo presence on Day 7 in yr $1(P=$ 0.2; Supplemental Figure S8; https://doi.org/10.3168/ jds.2017-14306) and yr $2(P=0.9$; Supplemental Figure S9; https://doi.org/10.3168/jds.2017-14306). The probability of embryo presence on Day 15 given that it is present on Day 7 is 0.946 in yr 1, indicating a low rate of embryo loss from Day 7 to Day 15 (assuming measurement of embryo presence on Day 7 is accurate and sensitive). This is consistent with the $15 \pm 2.3 \%$ of embryos that were categorized as UFO on Day 7 in yr 1 ( $\mathrm{n}=36$ from 238 embryos). In yr $2,17 \pm 3.2 \%$ of embryos were categorized as UFO on Day $7(n=24$ from 140 embryos). The loss of fertilized embryos from Day 7 to 15 is estimated to be $-6.3 \pm 3.9 \%$ in yr 1 and $-2 \pm 5.0 \%$ in yr 2 and is not significantly greater than $0 \%$, which indicates a low rate of embryo loss between Day 7 and 15 (based on yr 1 and 2, no evidence indicates that the rate of embryo loss between Day 7 and 15 is greater than 5\%). This contrasts with our previous in vitro ET trial where the estimated embryo survival probability from ET on Day 7 to recovery on Day 15 was 0.60 and suggests that in vivo and in vitro embryos have different temporal patterns of loss.

\section{Embryo Gene Expression}

Effect of Covariates on the Gene Expression Profile and Embryo Size on Day 7. Because the gene expression and embryos size on Day 7 are highly correlated, multivariate analysis can be used to assess the variables simultaneously and determine the role of different factors that produced them. The distribution in embryo cell number on Day 7 (based on stage) is log normal (Supplemental Figure S10; https://doi.org/10 $.3168 /$ jds.2017-14306). The nanostring gene expression data on Day 7 is very well described by a log-normal distribution with a detection limit of 1. Embryo cell number on Day 7 and gene expression data were therefore $\log$-transformed for analysis. A significant weak relationship was present between Day 7 progesterone and embryo cell number on Day $7\left(\mathrm{R}^{2}=0.08 ; P=0.01\right.$; Supplemental Figure S11; https://doi.org/10.3168/jds $.2017-14306)$. However, BCS $(P=0.8)$, BCS change $(P$ $=0.4)$, and DPP $(P=0.5)$ had no significant effects on Day 7 embryo size. A multivariate analysis indicated 
no effect of grade $(1,2$, and 3$)$ on the gene expression profile $(P=0.1)$. A multivariate analysis indicated no significant effects of Day 0 progesterone $(P=0.2)$, Day 7 progesterone $(P=0.5)$, BCS $(P=0.6)$, and DPP $(P=0.6)$ on the gene expression data (81 genes with gene expression greater than the limit of detection of the assay).

A second multivariate analysis (to investigate the effect of Day 7 embryo size on the Day 7 gene expression) indicates an effect of embryo size on the gene expression profile $(P=0.01$, i.e., gene expression profile is predictable based on embryo size). A high level of correlation structure $(\mathrm{R}=-0.6$ to 0.9$)$ was detected in the gene expression data (Supplemental Figure S12, https://doi .org/10.3168/jds.2017-14306; for the 81 genes with gene expression greater than the limit of detection of the assay, yellow denotes high positive correlation between genes in the estimated error variance-covariance matrix $\boldsymbol{\Sigma}$ in Equation [6]).

Our significant effect of embryo size on the gene expression profile is consistent with Barnwell et al. (2016) who transferred grade- 1 and grade- 3 embryos (compact morulas) on Day 6.5 and found that 348 genes were differentially expressed between conceptuses classified as short $(4.2 \mathrm{~mm})$ or long $(24.7 \mathrm{~mm})$ at Day 15 of gestation ( $\mathrm{n}=5$ embryos per group). However, Barnwell et al. (2016) found no differences in the Day 15 gene expression profiles between grade- 1 and grade-3 embryos, although grade-3 embryos were less likely to survive to Day 15.

Role of Embryo Stage on Gene Expression Profile. A one-way multivariate ANOVA to compare the multivariate means in the gene expression data grouped by embryo stage (M, TM, EB, B, XB) demonstrates that the first 2 canonical variables obtained provide good group separation (Figure 4). A dendrogram demonstrating the clusters among the group means based on a 1-way multivariate ANOVA is shown in Supplemental Figure S13 (https://doi.org/10.3168/ jds.2017-14306). The height of each node represents the distance between the 2 groups being connected. This analysis highlights that TM and EB have very similar gene expression profiles, $\mathrm{B}$ and XB have somewhat similar gene expression profiles, and $\mathrm{M}$ have very different gene expression profiles, which is consistent with the known changes in the embryo during the development process. This ability to differentiate embryo stage based on gene expression is consistent with other bovine in vivo preimplantation development studies (Kues et al., 2008; Jiang et al., 2014).

Using the Gene Expression Profile to Predict Embryo Size/Stage. The PLSR calibration and validation performance for phase 1 models based on the nanostring data ( $\mathrm{n}=96$ embryos) is shown in Figure
$5(\mathrm{LV}=2)$. A PLSR model for embryo size calibrated to two-thirds of the data $\left[\mathrm{R}^{2}=0.63, \mathrm{RMSE}=0.131\right.$ $\log _{10}$ (cell number), $\mathrm{n}=62$ ] has a validation $\mathrm{R}^{2}$ of 0.58 validated on the remaining one-third of data $[\mathrm{RMSE}=$ $0.135 \log _{10}$ (cell number), $\mathrm{n}=31$, slope $=0.84 \pm 0.13$, intercept $=0.31 \pm 0.25 \log _{10}$ (cell number), bias $=-0.03$ $\log _{10}$ (cell number)]; that is, the majority of the variance in embryo size $\left[\log _{10}\right.$ (cell number)] is predictable based on the gene expression profile (3 embryos had missing size information). The small reduction in prediction performance for embryo size between calibration $\left(\mathrm{R}^{2}=\right.$ $0.63)$ and validation $\left(R^{2}=0.58\right)$ is expected when we switch from training to testing data and the validation prediction performance remains acceptable. The validated model slope and intercept are not significantly different from 1 and 0 , respectively, and the bias is close to 0 . This indicates that the PLSR model can provide valid predictions of embryo cell number. The confusion matrix for the PLSR predictions of embryo stage (M, TM, EB, B, XB) are shown in Table 2. The model correctly classifies embryo stage in 19 out of 31 embryos for the validation data set. This is similar to the LDA model (Table 3), which correctly classifies embryo stage in 18 out of 31 embryos for the validation data set (although a direct comparison cannot be directly made because the LDA model is calibrated to the categorical embryo stage variable, whereas PLSR is calibrated to the continuous embryo size variable (Bereton and Loyd, 2014). The confusion matrix for the PLSR predictions of embryo grade and stage (e.g., B1, B2, and B3) for

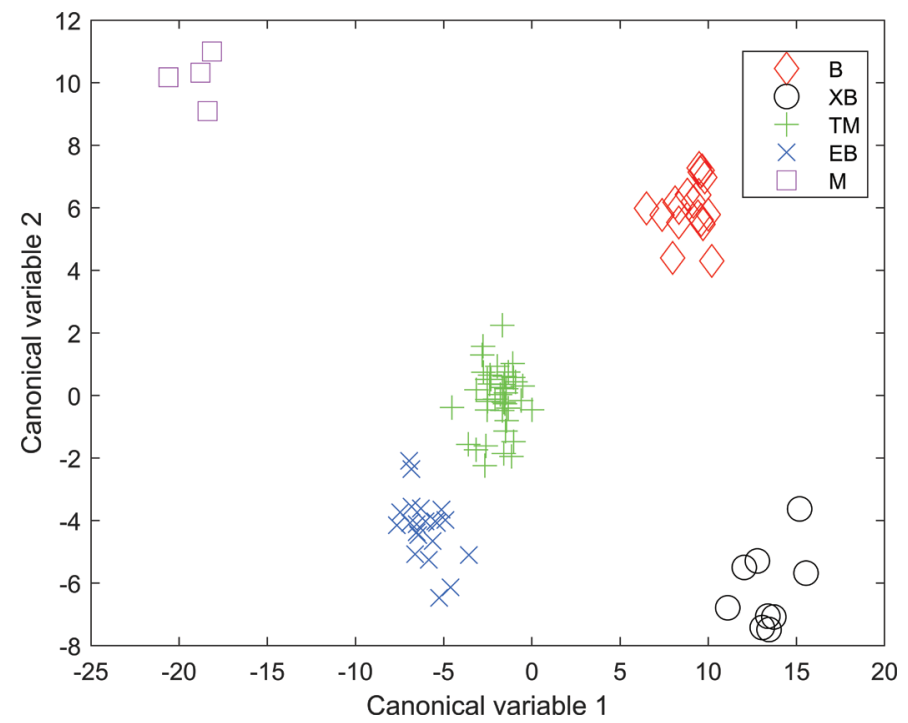

Figure 4. Grouped scatter plot of the first 2 canonical variables obtained from a 1-way multivariate ANOVA $(\mathrm{n}=93)$. The first 2 canonical variables provide good group separation. $\mathrm{M}=$ morula; $\mathrm{TM}=$ tight/compact morula; $\mathrm{EB}=$ early blastocyst; $\mathrm{B}=$ blastocyst; $\mathrm{XB}=$ expanding blastocyst. Color version available online. 
Table 2. The confusion matrix for the partial least squares regression (PLSR) predictions of embryo stage for calibration $(\mathrm{n}=62)$ and validation $(\mathrm{n}=31)$ data sets [element $(i, j)$ in the matrix are the number of observations known to be in group $i$ (row) but predicted to be in group $j$ (column) $]^{1}$

\begin{tabular}{lcrrrrllllll}
\hline Calibration & M & TM & EB & B & XB & Validation & M & TM & EB & B & XB \\
\hline M & 1 & 2 & 0 & 0 & 0 & M & 0 & 1 & 0 & 0 & 0 \\
TM & 1 & 18 & 8 & 0 & 0 & TM & 1 & 13 & 0 & 0 & 0 \\
EB & 0 & 7 & 7 & 0 & 0 & EB & 0 & 4 & 3 & 0 & 0 \\
B & 0 & 0 & 8 & 2 & 2 & B & 0 & 0 & 2 & 3 & 1 \\
XB & 0 & 0 & 0 & 5 & 1 & XB & 0 & 0 & 0 & 3 & 0 \\
\hline
\end{tabular}

${ }^{1} \mathrm{M}=$ morula; $\mathrm{TM}=$ tight/compact morula; $\mathrm{EB}=$ early blastocyst; $\mathrm{B}=$ blastocyst; $\mathrm{XB}=$ expanding blastocyst.

validation $(\mathrm{n}=31)$ data sets are listed in Supplemental Table S2 (https://doi.org/10.3168/jds.2017-14306). The PLSR models correctly classify embryo grade and stage in 6 out of 31 embryos for the validation data set. The RMSE for the PLSR embryo size model [RMSE = $0.135 \log _{10}$ (cell number)] is approximately double the difference between grades and stage $\left[\sim 0.07 \log _{10}\right.$ (cell number)] and the model provides poor prediction of grade and stage. The predictive performance of LDA models of embryo grade and stage were similar to the PLSR models with 8 out of 31 correct classifications of embryo grade and stage.

Key Genes Associated with Embryo Cell Size. The PLSR weights of the 194 gene expression predictors in the 2 PLSR components for the model for embryo size are shown in Supplemental Figure S14 (https:// doi.org/10.3168/jds.2017-14306). These weights specify the importance of each gene on embryo cell number on Day 7. The genes in the 2nd component (red) with PLS weight greater than 0.013 are $B C A M, D S C$, HNF4A, HSD3B1, KRT18, KRT8, PAG2, PTGS2, $S F N$, and SLC16A\%. The genes BCAM and SLC16A7 are considered to be "hub genes" and are expressed in mouse, human, and bovine embryos and considered to be highly conserved and expressed across species (Jiang et al., 2014). These genes are highly conserved between species, which is consistent with their role in early embryonic development (Negrón-Pérez et al., 2017). The KRT8 is considered to be a predictor of embryo survival (Ghanem et al., 2011) and KRT8 and $S F N$ were found to be upregulated in TE cell populations during early bovine blastocyst growth to Day 7 and Day 8.75 (Negrón-Pérez et al., 2017), and we also found KRT18 mis-expressed in clone embryos (Somers et al., 2006). The other genes are all upregulated in the placenta portion of the embryo. The genes in the 2nd component (red) with PLS weight less than -0.013 are CCNB1, KLF4, OTX2, SMAD3, SOX2, SPIC, and $S T A T 3$. All these genes are upregulated in the inner cell mass cells (except possibly CCNB1). The gene in the first component (blue) with PLS weight greater than 0.013 is PTGS2, and no genes in the first compo- nent (blue) have a PLS weight less than -0.013 . The PTGS2 appears in each component and is positively correlated with embryo size, which is consistent with gene expression in Day 15 embryos after ET on Day 7 (Shorten et al., 2018) and Day 7 embryos in cows that become pregnant (Ghanem et al., 2011). The PTGS2 is also the best single gene predictor of embryo size on Day 7. This is also consistent with the role of PTGS2 on increasing embryo survival and promoting ED development and embryo elongation during development to both Day 8 and Day 15 (Nuttinck et al., 2017). Moraes et al. (2018) also identified that PTGS2 was a critical enzyme that may play a central role in gene expression networks in high- and sub-fertile conceptuses. The role of embryo stage (M, TM, EB, B, XB) on the gene expression of nanostring genes with a mean $\log _{10}$ gene expression greater than 0.6 is shown in Supplemental Figure S15 (https://doi.org/10.3168/jds.2017-14306)

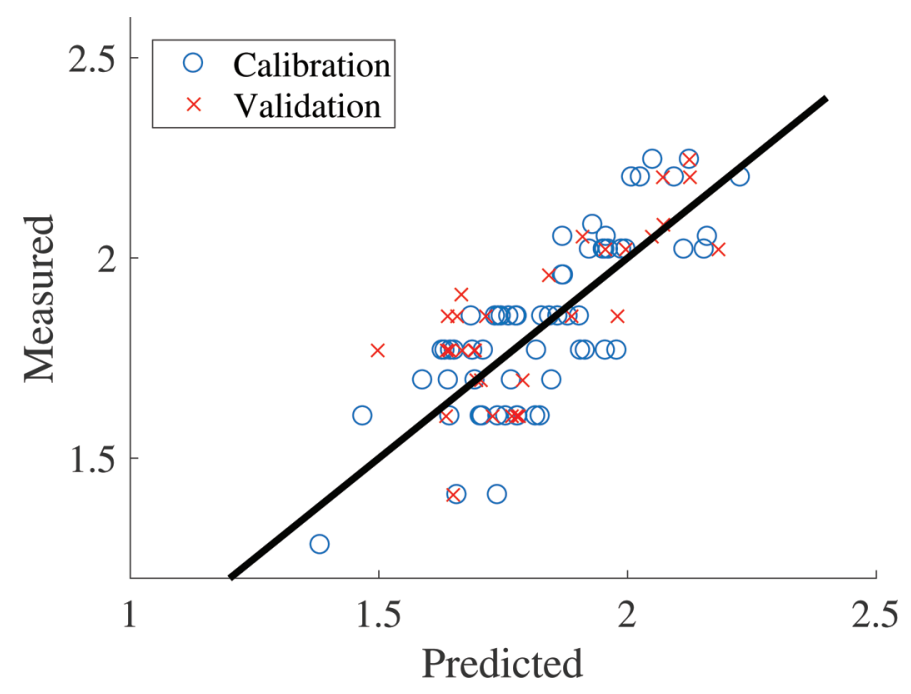

Figure 5. The partial least squares regression (PLSR) model performance for embryo size $\left[\log _{10}\right.$ (cell number)]. A PLSR model calibrated to two-thirds of the data $\left(\mathrm{R}^{2}=0.63\right)$ has a validation $\mathrm{R}^{2}$ of 0.58 (validated on the remaining one-third of data); that is, the gene expression profile can be used to predict embryo size $\left[\log _{10}\right.$ (cell number)]. Color version available online. 
Table 3. The confusion matrix for the linear discriminant analysis predictions of embryo stage for calibration $(\mathrm{n}=62)$ and validation $(\mathrm{n}=31)$ data sets [element $(i, j)$ in the matrix are the number of observations known to be in group $i$ (row) but predicted to be in group $j$ (column) $]^{1}$

\begin{tabular}{|c|c|c|c|c|c|c|c|c|c|c|c|}
\hline Calibration & M & $\mathrm{TM}$ & $\mathrm{EB}$ & B & $\mathrm{XB}$ & Validation & M & $\mathrm{TM}$ & $\mathrm{EB}$ & B & $\mathrm{XB}$ \\
\hline $\mathrm{M}$ & 2 & 0 & 1 & 0 & 0 & $\mathrm{M}$ & 0 & 1 & 0 & 0 & 0 \\
\hline TM & 2 & 19 & 3 & 3 & 0 & TM & 2 & 10 & 2 & 0 & 0 \\
\hline EB & 0 & 4 & 10 & 0 & 0 & EB & 1 & 3 & 2 & 0 & 1 \\
\hline B & 0 & 0 & 0 & 11 & 1 & B & 0 & 1 & 0 & 4 & 1 \\
\hline XB & 0 & 0 & 0 & 1 & 5 & XB & 0 & 0 & 0 & 1 & 2 \\
\hline
\end{tabular}

${ }^{1} \mathrm{M}=$ morula; $\mathrm{TM}=$ tight/compact morula; $\mathrm{EB}=$ early blastocyst; $\mathrm{B}=$ blastocyst; $\mathrm{XB}=$ expanding blastocyst.

where PTGS2 exhibits a 25-fold increase in expression between morula to expanding blastocyst stages.

Gene Clustering Based on Co-Expression of Genes. A hierarchical clustering of the nanostring genes with a mean $\log _{10}$ gene expression greater than 0.6 is shown in Figure 6 . The height of each node represents the distance between the 2 groups being connected. Five main groups can be seen in Figure 6. Group 1 contains genes that have been associated with successful pregnancies after the transfer of grade 1 blastocysts after biopsy $(A C T B, N T 1)$. Downregulation of KRT8 and $R P L P O$ is required for pregnancy establishment/ calf delivery and involved in protein synthesis and binding. Group 2 contains genes associated with blastocyst development (including KRT18). Group 3 contains predominantly binding genes and includes STAT3, SPIC, and IL6R. Group 4 contains genes linked to receptor activity and binding including TGF2B, ACVR2B, and LEPROT. Cytokine receptor activity genes include TGF2B, ACVR2B, and LEPROT. Binding and nucleic acid binding genes include $S M A D 4$ and MRNA splicing factor (SF3A1). Catalytic activity genes include PGK1.

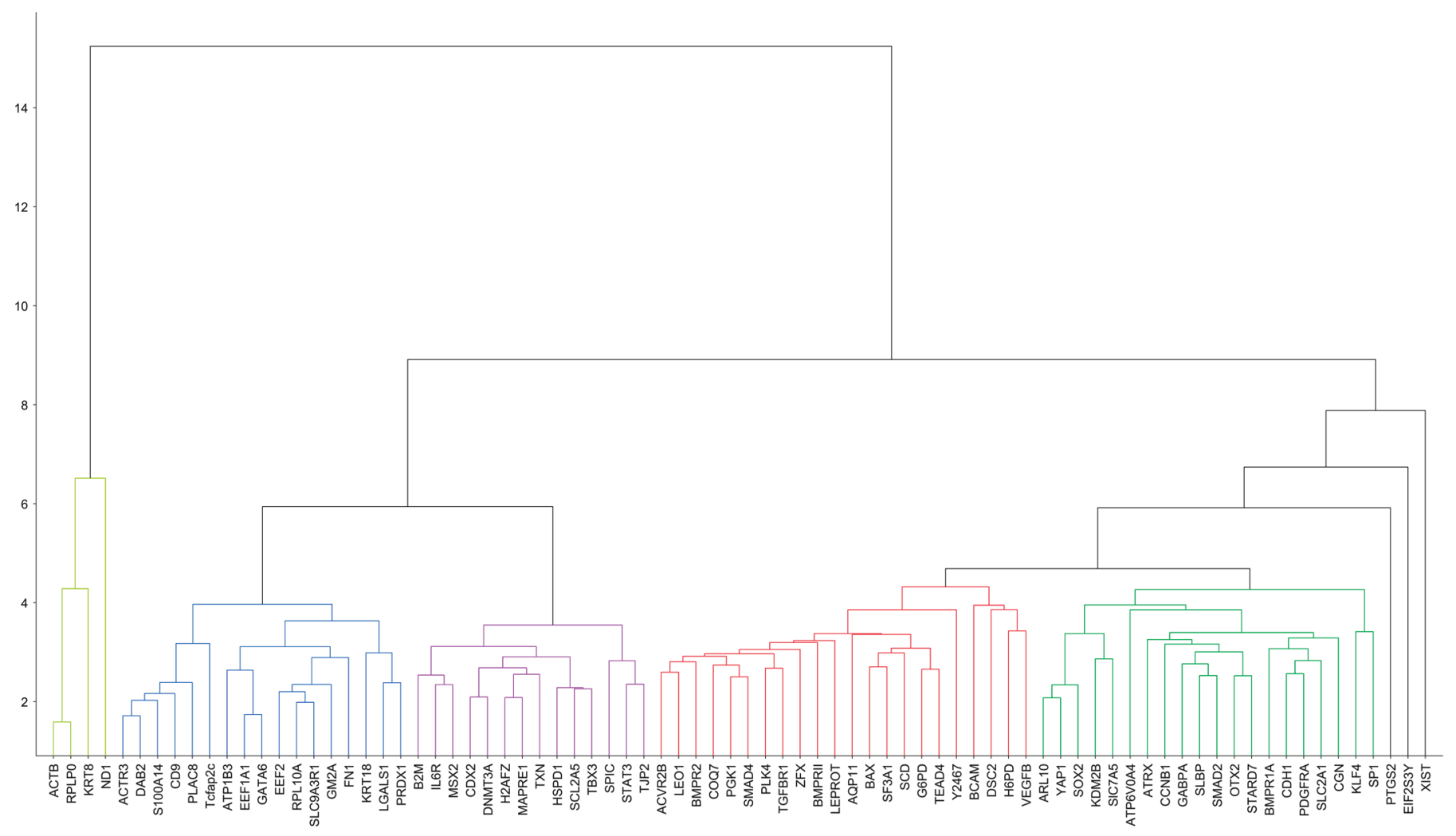

Figure 6. Hierarchical clustering of the nanostring genes with a mean $\log _{10}$ gene expression greater than 0.6. The height of each node represents the distance between the 2 groups being connected. Each nonblack color denotes a different group (groups 1-5, left to right). [Group 1 (ACTB-ND1), group 2 (ACTR3-PRDX1), group 3 (B2M-TJP2, group 4 (ACVR2B-VEGFB), group 5 (ARL10-SP1)]. Color version available online. 
Group 5 contains binding and catalytic genes associated with the morula stage (including SOX2, SMAD2, OTX2, KLF4, and CCNB1). The clustering analysis demonstrates the level of co-expression of genes that occur during the coordinated changes in the gene network pathways in embryonic development. The coexpression of the genes, and the fact that they have similar annotation in Gene Ontology (GO) database (GO Consortium), provides us with candidates that may have a role in embryo development.

\section{CONCLUSIONS}

Progesterone is not a strong predictor of in vivo embryo growth to Day 16. In fact, in vivo embryos are 3 times less sensitive to progesterone than in vitro-transferred embryos (up to Day 15). These results highlight a need for caution when extrapolating the results of in vitro ET studies to the in vivo situation. The similar variance in measured and predicted (based on Day 15 length) Day 7 embryo stage indicate low stochastic perturbations for in vivo embryo growth. Furthermore, Day 7 embryo stage could be well predicted based on the gene expression profile.

\section{ACKNOWLEDGMENTS}

This work was supported by a partnership (DRCX1302) between the New Zealand Ministry for Business, Innovation and Employment and New Zealand dairy farmers through DairyNZ Inc. (Hamilton) and via AgResearch (Hamilton) Core funding.

\section{REFERENCES}

Barnwell, C. V., P. W. Farin, C. M. Ashwell, W. T. Farmer, S. Galphin, and C. E. Farin. 2016. Differences in mRNA populations of short and long bovine conceptuses on Day 15 of gestation. Mol. Reprod. Dev. 83:424-441.

Bates, D. M., and D. G. Watts. 2007. Nonlinear Regression Analysis and Its Applications. John Wiley \& Sons, New York, NY.

Bazer, F. W., R. M. Roberts, and W. W. Thatcher. 1979. Actions of hormones on the uterus and effect on conceptus development. J. Anim. Sci. 49:35-45.

Bereton, R. G., and G. R. Loyd. 2014. Partial least squares discriminant analysis: Taking the magic away. J. Chem. 28:213-225.

Berg, D. K., J. van Leeuwen, S. Beaumont, M. Berg, and P. L. Pfeffer. 2010. Embryo loss in cattle between Days 7 and 16 of pregnancy. Theriogenology 73:250-260.

Carter, F., N. Forde, P. Duffy, M. Wade, T. Fair, M. A. Crowe, A. C. Evans, D. A. Kenny, J. F. Roche, and P. Lonergan. 2008. Effect of increasing progesterone concentration from day 3 of pregnancy on subsequent embryo survival and development in beef heifers. Reprod. Fertil. Dev. 20:368-375.

Cheng, J. H., and D. W. Sun. 2015. Recent applications of spectroscopic and hyperspectral imaging techniques with chemometric analysis for rapid inspection of microbial spoilage in muscle foods. Compr. Rev. Food Sci. Food Saf. 14:478-490.

Clemente, M., J. de La Fuente, T. Fair, A. Al Naib, A. Gutierrez-Adan, J. F. Roche, D. Rizos, and P. Lonergan. 2009. Progesterone and conceptus elongation in cattle: A direct effect on the embryo or an indirect effect via the endometrium? Reproduction 138:507-517.

Diskin, M. G., and D. G. Morris. 2008. Embryonic and early foetal losses in cattle and other ruminants. Reprod. Domest. Anim. 43:260-267.

Forde, N., M. E. Beltman, G. B. Duffy, P. Duffy, J. P. Mehta, P. O'Gaora, J. F. Roche, P. Lonergan, and M. A. Crowe. 2011. Changes in the endometrial transcriptome during the bovine estrous cycle: Effect of low circulating progesterone and consequences for conceptus elongation. Biol. Reprod. 84:266-278.

Garrett, J. E., R. D. Geisert, M. T. Zavy, and G. L. Morgan. 1988 Evidence for maternal regulation of early conceptus growth and development in beef cattle. J. Reprod. Fertil. 84:437-446.

Ghanem, N., D. Salilew-Wondim, A. Gad, D. Tesfaye, C. Phatsara, E. Tholen, C. Looft, K. Schellander, and M. Hoelker. 2011. Bovine blastocysts with developmental competence to term share similar expression of developmentally important genes although derived from different culture environments. Reproduction 142:551-564.

Gilks, W. R., A. Richardson, and D. J. Spiegelhalter. 1996. Markov chain Monte Carlo in practice. Chapman \& Hall, London.

Gray, C. A., R. C. Burghardt, G. A. Johnson, F. W. Bazer, and T. E. Spencer. 2002. Evidence that absence of endometrial gland secretions in uterine gland knockout ewes compromises conceptus survival and elongation. Reproduction 124:289-300.

Jiang, Z., J. Sun, H. Dong, O. Luo, X. Zheng, C. Obergfell, Y. Tang, J. Bi, R. O'Neill, Y. Ruan, J. Chen, and X. Tian. 2014. Transcriptional profiles of bovine in vivo pre-implantation development. BMC Genomics 15:756.

Johnson, D. S., R. P. Barry, and R. T. Bowyer. 2004. Estimating timing of life history events with coarse data. J. Mammal. 85:932-939.

Kues, W. A., S. Sudheer, D. Herrmann, J. W. Carnwath, V. Havlicek, U. Besenfelder, H. Lehrach, J. Adjaye, and H. Niemann. 2008. Genome-wide expression profiling reveals distinct clusters of transcriptional regulation during bovine preimplantation development in vivo. Proc. Natl. Acad. Sci. USA 105:19768-19773.

Ledgard, A. M., S. Meier, and A. J. Peterson. 2011. Evaluation of the uterine environment early in pregnancy establishment to characterise cows with a potentially superior ability to support conceptus survival. Reprod. Fertil. Dev. 23:737-747.

Lonergan, P., P. Monaghan, D. Rizos, M. P. Boland, and I. Gordon. 1994. Effect of follicle size on bovine oocyte quality and developmental competence following maturation, fertilization, and culture in vitro. Mol. Reprod. Dev. 37:48-53.

Mann, G. E., M. D. Fray, and G. E. Lamming. 2006. Effects of time of progesterone supplementation on embryo development and interferon- $\tau$ production in the cow. Vet. J. 171:500-503.

Moraes, J. G. N., S. K. Behura, T. W. Geary, P. J. Hansen, H. L. Neibergs, and T. E. Spencer. 2018. Uterine influences on conceptus development in fertility-classified animals. Proc. Natl. Acad. Sci. USA 115:E1749-E1758.

Morris, D., and M. G. Diskin. 2008. Effect of progesterone on embryo survival. Animal 2:1112-1119.

Negrón-Pérez, V., Y. Zang, and P. J. Hansen. 2017. Single-cell gene expression of the bovine blastocyst. Reproduction 154:627-644.

Nuttinck, F., A. Jouneau, G. Charpigny, I. Hue, C. Richard, P. Adenot, S. Ruffini, L. Laffont, M. Chebrout, V. Duranthon, and B. Marquant-Le Guinne. 2017. Prosurvival effect of cumulus prostaglandin $\mathrm{G} / \mathrm{H}$ synthase 2 /prostaglandin2 signaling on bovine blastocyst: Impact on in vivo posthatching development. Biol. Reprod. 96:531-541.

Ozawa, M., M. Sakatani, J. Yao, S. Shanker, F. Yu, R. Yamashita, S. Wakabayashi, K. Nakai, K. B. Dobbs, M. J. Sudano, W. G. Farmerie, and P. J. Hansen. 2012. Global gene expression of the inner cell mass and trophectoderm of the bovine blastocyst. BMC Dev. Biol. 12:33.

Pavlok, A., A. Lucas-Hahn, and H. Niemann. 1992. Fertilization and developmental competence of bovine oocytes derived from different categories of antral follicles. Mol. Reprod. Dev. 31:63-67.

Peters, A. R. 1996. Embryo mortality in the cow. Anim. Breed. Abstr. 64:587-598. 
Rencher, A. C. 2002. Methods of Multivariate Analysis. 2nd ed. John Wiley \& Sons Inc., New York, NY.

Robinson, R. S., M. D. Fray, D. C. Wathes, G. E. Lamming, and G. E. Mann. 2006. In vivo expression of interferon tau mRNA by the embryonic trophoblast and uterine concentrations of interferon tau protein during early pregnancy in the cow. Mol. Reprod. Dev. $73: 470-474$.

Roche, J. R., C. R. Burke, S. Meier, and C. G. Walker. 2011. Nutrition $\mathrm{x}$ reproduction interaction in pasture-based systems: Is nutrition a factor in reproductive failure? Anim. Prod. Sci. 51:1045-1066.

Roche, J. R., P. G. Dillon, C. R. Stockdale, L. H. Baumgard, and M. J. VanBaale. 2004. Relationships among international body condition scoring systems. J. Dairy Sci. 87:3076-3079.

Satterfield, M. C., F. W. Bazer, and T. E. Spencer. 2006. Progesterone regulation of preimplantation conceptus growth and galectin 15 (LGALS15) in the ovine uterus. Biol. Reprod. 75:289-296.

Shorten, P. R., A. M. Ledgard, M. Donnison, P. L. Pfeffer, R. M. McDonald, and D. K. Berg. 2018. A mathematical model of the interaction between bovine blastocyst developmental stage and progesterone stimulated uterine factors on differential embryonic development observed on gestational day 15. J. Dairy Sci. 101:736-751.

Shorten, P. R., A. R. O'Connell, K. J. Demmers, S. J. Edwards, N G. Cullen, and J. L. Juengel. 2013. Effect of age, weight, and sire on embryo and fetal survival in sheep. J. Anim. Sci. 91:4641-4653.

Shorten, P. R., A. J. Peterson, A. R. O'Connell, J. L. Juengel, K. P. McNatty, and T. K. Soboleva. 2010. A mathematical model of pregnancy recognition in mammals. J. Theor. Biol. 266:62-69.

Somers, J., C. Smith, M. Donnison, D. N. Wells, H. Henderson, L. McLeay, and P. L. Pfeffer. 2006. Gene expression profiling of individual bovine nuclear transfer blastocysts. Reproduction 131:1073-1084.
Spencer, T. E. 2013. Early pregnancy: Concepts, challenges, and potential solutions. Anim. Front. 3:48-55.

Spencer, T. E., G. A. Johnson, F. W. Bazer, R. C. Burghardt, and M. Palmarini. 2007. Pregnancy recognition and conceptus implantation in domestic ruminants: Roles of progesterone, interferons and endogenous retroviruses. Reprod. Fertil. Dev. 19:65-78.

Spencer, T. E., G. A. Johnson, R. C. Burghardt, and F. W. Bazer. 2004. Progesterone and placental hormone actions on the uterus: Insights from domestic animals. Biol. Reprod. 71:2-10.

Tsai, S. J., and M. C. Wiltbank. 1998. Prostaglandin F2 $\alpha$ regulates distinct physiological changes in early and mid-cycle bovine corpora lutea. Biol. Reprod. 58:346-352.

Ulbrich, S. E., E. Wolf, and S. Bauersachs. 2012. Hosting the preimplantation embryo: Potentials and limitations of different approaches for analysing embryo-endometrium interactions in cattle. Reprod. Fertil. Dev. 25:62-70.

Ushijima, H., K. Akiyama, and T. Tajima. 2009. Classification of morphological changes based on the number of cleavage divisions in bovine embryos. J. Reprod. Dev. 55:83-87.

Van Soom, A., M. L. Boerjan, P. E. J. Bols, G. Vanroose, A. Lein, M. Coryn, and A. de Kruif. 1997. Timing of compaction and inner cell allocation in bovine embryos produced in vivo after superovulation. Biol. Reprod. 57:1041-1049.

Wold, S., M. Sjöström, and L. Eriksson. 2001. PLS-regression: A basic tool of chemometrics. Chemom. Intell. Lab. Syst. 58:109-130.

Zhao, X. M., L. S. Cui, H. S. Hao, H. Y. Wang, S. J. Zhao, W. H. Du, D. Wang, Y. Liu, and H. B. Zhu. 2016. Transcriptome analyses of inner cell mass and trophectoderm cells isolated by magnetic-activated cell sorting from bovine blastocysts using single cell RNAseq. Reprod. Domest. Anim. 51:726-735. 